\title{
PENYULUHAN PEMANFAATAN PANGAN FUNGSIONAL PADA MASA PANDEMI COVID-19 DI FORUM KELOMPOK WANITA TANI SEKAR ARUM TANGERANG SELATAN
}

\author{
Tagor M. Siregar¹, Lucia Soedirga', Wenny Sinaga ${ }^{1}$, Yuniwaty Halim ${ }^{1}$ \\ ${ }^{1}$ Program Studi Teknologi Pangan Fakultas Sains Dan Teknologi Universitas Pelita Harapan
}

tagor.siregar@uph.edu, lucia.soedirga@uph.edu, wenny.sinaga@uph.edu ,yuniwaty.halim@uph.edu

\begin{abstract}
Abstrak
Forum kelompok wanita tani (KWT) Sekar Arum merupakan kelompok masyarakat di Tangerang Selatan yang melakukan budidaya tanaman pangan. Pada masa pandemi Covid-19 masyarakat diharapkan memiliki asupan makanan sehat yang dapat meningkatkan imunitas tubuh. Pangan fungsional adalah pangan dengan kandungan komponen aktifnya dapat memberikan manfaat bagi kesehatan. Sebagian besar anggota Forum KWT Sekar Arum Tangerang Selatan memiliki pengetahuan yang terbatas mengenai manfaat kesehatan bahan pangan yang telah dibudidayakan. Sebagai respon atas kondisi ini, Program Studi Teknologi Pangan UPH melaksanakan kegiatan penyuluhan pemanfaatan pangan fungsional yang bertujuan agar masyarakat dapat memanfaatkan pangan lokal yang dibudidayakan sebagai sumber pangan fungsional. Pada tahap persiapan dilakukan proses diskusi dengan pengurus Forum KWT Sekar Arum dan Dinas Ketahanan Pangan, Pertanian dan Perikanan Kota Tangerang Selatan untuk menentukan dan memastikan topik, materi dan teknis pelaksanaan penyuluhan. Pelaksanaan penyuluhan dilakukan secara webinar menggunakan platform zoom meeting. Materi penyuluhan meliputi definisi, jenis komponen aktif dan manfaat fisiologis pangan fungsional. Penyuluhan diikuti oleh 87 peserta yang mewakili beberapa KWT di Tangerang Selatan. Evaluasi terhadap kuesioner menunjukkan 98,85\% peserta menyatakan penyuluhan dapat diikuti dengan baik dan sangat bermanfaat serta menginginkan adanya penyuluhan atau pelatihan berkelanjutan dengan topik yang disesuaikan dengan kebutuhan dan potensi sumber daya yang ada.
\end{abstract}

Kata Kunci : covid-19, kelompok wanita tani, komponen aktif, imunitas, pangan fungsional

\section{PENDAHULUAN}

Universitas Pelita Harapan (UPH) memiliki misi yang antara lain adalah berpartisipasi secara redemtif dalam pengembangan individu dan masyarakat bagi kemuliaan Tuhan. Berdasarkan misi tersebut, maka Program Studi Teknologi Pangan UPH secara berkala melaksanakan pengabdian kepada masyarakat melalui kegiatan penyuluhan dan pelatihan dengan topik-topik yang mencakup aplikasi Ilmu dan Teknologi Pangan.

Forum Kelompok Wanita Tani (KWT) Sekar Arum merupakan suatu forum dimana tergabung beberapa Kelompok Wanita Tani yang ada di wilayah Tangerang Selatan. Kegiatan utama Forum KWT ini adalah membudidayakan tanaman pangan seperti tanaman rempah-rempah dan tanaman hidroponik. Beberapa jenis tanaman telah 
dibudidayakan, antara lain sereh, jahe, kencur, kangkung, bayam merah, pok choy, dan kelor (Siregar et al., 2020). Hasil kegiatan budidaya ini, selain dimanfaatkan untuk kebutuhan sehari-hari juga berpotensi diolah menjadi produk pangan yang bernilai ekonomi tinggi dan bermanfaat untuk kesehatan. Pada saat ini, sebagian besar anggota Forum KWT Sekar Arum masih memiliki pengetahuan yang terbatas mengenai manfaat kesehatan dan cara pengolahan bahan pangan lokal yang dibudidayakan menjadi produk pangan fungsional.

Pangan fungsional adalah pangan yang karena kandungan komponen aktifnya dapat memberikan manfaat bagi kesehatan, di luar manfaat yang diberikan oleh zat-zat gizi yang terkandung di dalamnya. Pangan fungsional tidak berbentuk kapsul, tablet atau bubuk yang mengandung komponen aktif, meskipun bermanfaat bagi kesehatan. Komponen aktif merupakan senyawa aktif dalam pangan fungsional yang bertanggung jawab atas berlangsungnya reaksireaksi metabolisme yang menguntungkan kesehatan seperti mencegah timbulnya penyakit dan meningkatkan daya tahan tubuh (Astawan, 2011 dan Subroto, 2008). Salah satu faktor penyebab timbulnya penyakit Covid-19 adalah daya tahan tubuh yang sangat ditentukan oleh jenis dan pola asupan makanan.

Agar dapat dikategorikan sebagai pangan fungsional, maka bahan pangan atau produk pangan harus dapat dikonsumsi sebagaimana layaknya makanan atau minuman dengan karakteristik sensori seperti penampakan, warna, tekstur dan cita rasa yang dapat diterima (Astawan, 2011).

Berdasarkan hal-hal yang telah diuraikan tersebut, maka Program Studi Teknologi Pangan UPH merespon dengan melakukan kegiatan penyuluhan mengenai pemanfaatan pangan fungsional pada masa pandemi Covid-19. Pelaksanaan kegiatan penyuluhan ini diharapkan dapat bermanfaat bagi Forum Kelompok Wanita Tani Sekar Arum dalam meningkatkan pemahaman tentang manfaat kesehatan dan pengolahan tanaman pangan yang telah dibudidayakan. Setelah mengikuti kegiatan ini, setiap anggota Forum KWT Sekar Arum juga diharapkan dapat membagikan pengetahuan dan pengalaman yang diperoleh kepada masyarakat sekitar sehingga pada akhirnya dapat membantu tercapainya peningkatan kesehatan dan kesejahteraan.

\section{METODE}

Pelaksanaan kegiatan Pengabdian kepada masyarakat $(\mathrm{PkM})$ dimulai dari tahap persiapan yang berupa diskusi secara daring dengan pengurus Forum KWT Sekar Arum dan salah seorang staf Dinas Ketahanan Pangan, Pertanian dan Perikanan kota Tangerang Selatan pada bulan September 2020. Diskusi dilakukan untuk menentukan dan memastikan topik, materi serta bentuk penyuluhan yang sesuai dengan kondisi, potensi sumber daya dan kebutuhan anggota Forum KWT pada masa pandemi Covid-19. Hasil diskusi menyepakati bahwa bentuk kegiatan adalah penyuluhan dengan topik Pemanfaatan Pangan Fungsional berbasis tanaman pangan yang dibudidayakan oleh Forum KWT Sekar Arum.

Selanjutnya, tim PkM-UPH menyiapkan materi penyuluhan yang diperoleh dari materi perkuliahan dan hasil penelitian tentang pangan fungsional yang sudah dilakukan di Program Studi Teknologi Pangan UPH serta penelusuran pustaka tentang tanaman pangan yang dibudidayakan dan manfaat kesehatannya.

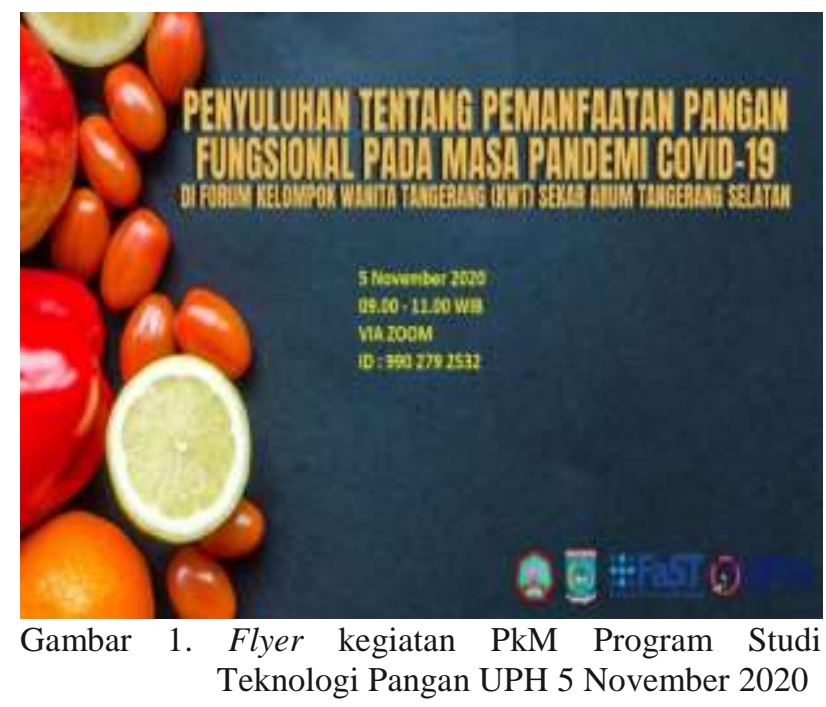

Di akhir tahap persiapan, tim PkM-UPH melakukan penyusunan dan pembuatan materi penyuluhan berupa slide presentasi 
(ms-powerpoint), menyiapkan dan menyediakan media penyuluhan secara virtual (webinar) berupa akses untuk media zoom meeting dan youtube serta koordinasi dengan tim dari Forum KWT Sekar Arum dan Dinas Ketahanan Pangan, Pertanian dan Perikanan kota Tangerang Selatan terkait susunan acara pelaksanaan Pengabdian Kepada Masyarakat.

\section{HASIL DAN PEMBAHASAN}

\section{Profil Forum KWT Sekar Arum Tangerang Selatan}

Forum KWT Sekar Arum merupakan forum dimana beberapa KWT yang ada di Tangerang Selatan bergabung, seperti KWT Cemara dan KWT Dumay yang berada di wilayah Pamulang. Setiap KWT yang tergabung dalam Forum KWT Sekar Arum memiliki kepengurusan dan kegiatan yang beragam sesuai dengan potensi dan kondisi masingmasing KWT. Pada umumnya kegiatan KWT yang ada di Tangerang Selatan adalah membudidayakan tanaman pangan seperti tanaman rempah-rempah dan tanaman hidroponik yaitu sereh, jahe, kunyit, lengkuas, kencur, pokchoy, bayam merah dan kelor (Siregar et al., 2020).

Dalam melaksanakan kegiatan budidaya tanaman pangan ini, Forum KWT Sekar Arum dibina dan difasilitasi oleh Pemerintah Kota Tangerang Selatan dalam hal ini Dinas Ketahanan Pangan, Pertanian dan Perikanan.

Kegiatan Penyuluhan ini sejalan dengan program kerja Dinas Ketahanan Pangan, Pertanian dan Perikanan kota Tangerang Selatan pada masa pandemi Covid-19 dalam memberdayakan masyarakat di bidang pertanian khususnya yang berkaitan dengan kegiatan pasca panen (Siregar et al., 2020)

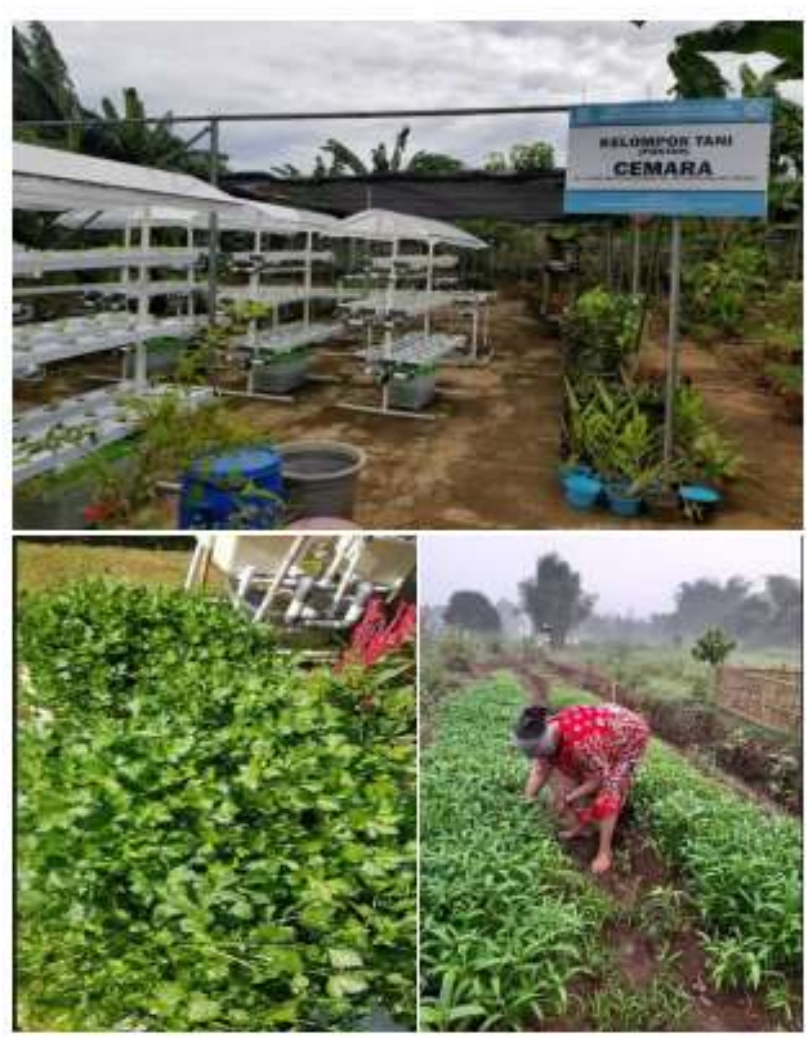

Gambar 2. Kondisi Kebun Yang dikelola salah satu KWT anggota Forum KWT Sekar Arum Tangerang Selatan

Sumber: Siregar et al., 2020

\section{Materi Penyuluhan Pemanfaatan Pangan Fungsional}

Berdasarkan hasil diskusi secara daring dengan pengurus Forum KWT Sekar Arum dan salah seorang staf Dinas Ketahanan Pangan, Pertanian dan Perikanan kota Tangerang Selatan, maka tim PkM-UPH menyiapkan dan menyusun materi penyuluhan "Pemanfaatan Pangan Fungsional Pada Masa Pandemi Covid-19", yang mencakup:

- Latar belakang dan definisi Pangan Fungsional

- Definisi Covid-19

- Perkembangan kasus Covid-19 di Indonesia per-november 2020

- Hubungan antara imunitas tubuh dengan pangan fungsional

- Jenis komponen aktif: vitamin, mineral, probiotik, serat pangan, fitosterol dan antioksidan

- Manfaat fisiologis komponen aktif 
- Produk Pangan Fungsional dan manfaat kesehatannya: pangan terfermentasi, produk dari tanaman herbal dan produk dari tanaman hortikultura.

\section{Pelaksanaan Kegiatan Penyuluhan}

Kegiatan Pengabdian kepada Masyarakat (PkM) Program Studi Teknologi Pangan UPH dengan Forum KWT Sekar Arum Tangerang Selatan dilaksanakan secara virtual (webinar), oleh karena adanya kebijakan PSBB (Pembatasan Sosial Berskala Besar) di wilayah Tangerang Raya pada masa pandemi Covid-19.

Kegiatan PkM melalui webinar ini dilaksanakan pada tanggal 5 November 2020 pada pukul 09.00 - 11.30 WIB. Kegiatan ini diikuti oleh 87 orang peserta yang merupakan perwakilan dari setiap KWT yang tergabung dalam Forum KWT Sekar Arum Tangerang Selatan. Tim pelatihan terdiri dari 4 orang dosen dan 2 orang mahasiswa Program Studi Teknologi Pangan UPH.

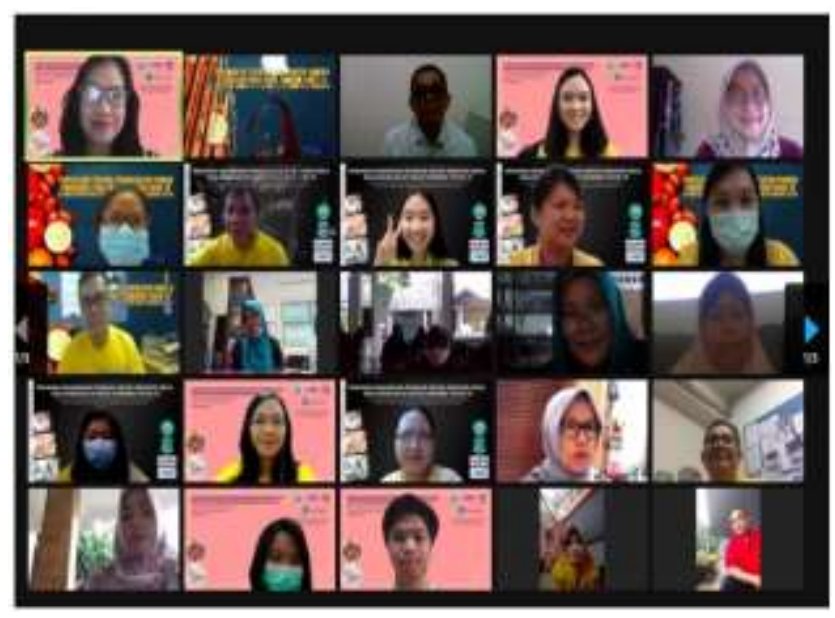

Gambar 3. Suasana Pembukaan Kegiatan PkM Prodi. Teknologi Pangan UPH serta Sambutan oleh Ketua Forum KWT Sekar Arum (Hj. Riska, $\mathrm{SH})$ dan Kepala Bidang Pertanian dan Peternakan, Dinas Ketahanan Pangan, Pertanian dan Perikanan Kota Tangerang Selatan (Ir. H.M Ramdan, MM)

Kegiatan PkM berupa Penyuluhan Pemanfaatan Pangan Fungsional ini dibagi menjadi dua sesi, dimana sesi pertama berupa presentasi dan pemaparan mengenai Pemanfaatan Pangan
Fungsional. Adapun materi yang disampaikan dalam penyuluhan disusun berdasarkan materi perkuliahan dan hasil penelitian tentang pangan fungsional yang sudah dilakukan di Program Studi Teknologi Pangan UPH serta penelusuran pustaka tentang tanaman pangan yang dibudidayakan oleh Forum KWT Sekar Arum dan manfaat kesehatannya. Seluruh materi penyuluhan ini dirangkum dalam bentuk slide presentasi (ms-powerpoint) yang kemudian setelah kegiatan PkM juga dapat diakses dan dibagikan oleh seluruh peserta melalui media online youtube.

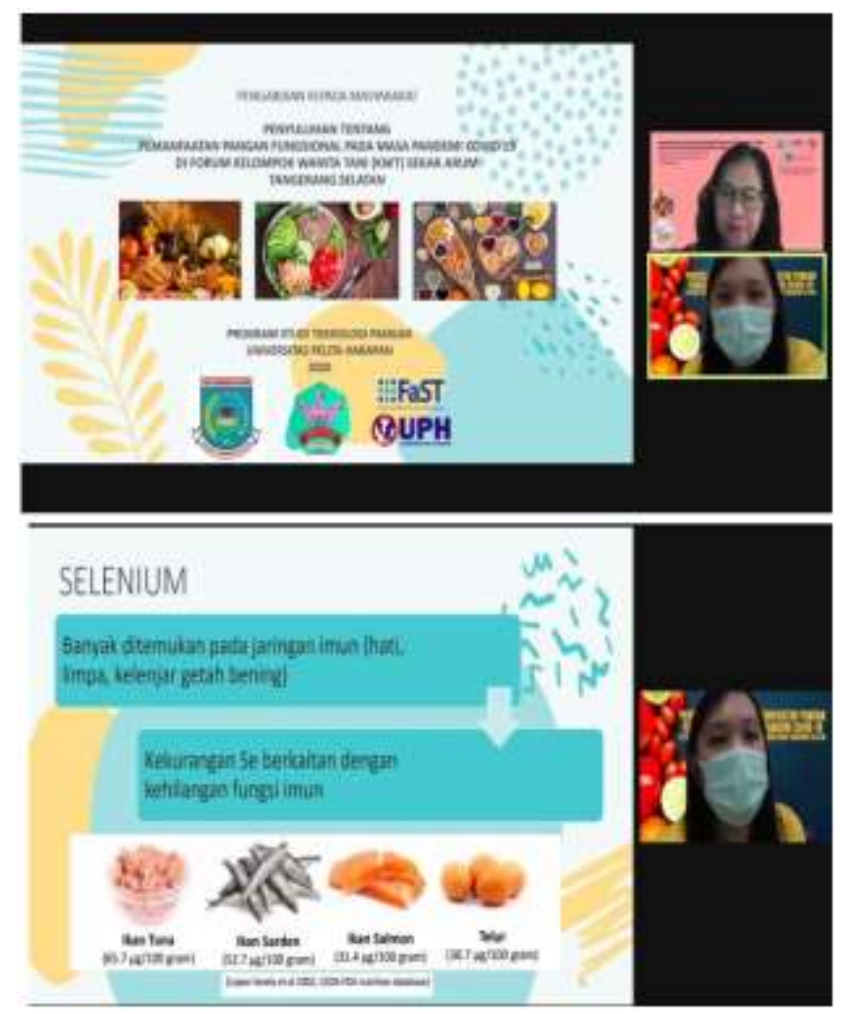

Gambar 4. Penjelasan materi penyuluhan tentang Pemanfaatan Pangan Fungsional Pada Masa Pandemi Covid-19 oleh Tim PkM$\mathrm{UPH}$

Setelah pemaparan materi selesai dilakukan, sesi kedua berupa kegiatan diskusi dan tanya jawab langsung dilakukan untuk mengetahui respon dan pemahaman peserta mengenai pangan fungsional, jenis-jenis komponen aktif dalam bahan pangan, jenis-jenis produk pangan fungsional, pengolahan 
pangan fungsional dan manfaat fisiologis pangan fungsional.
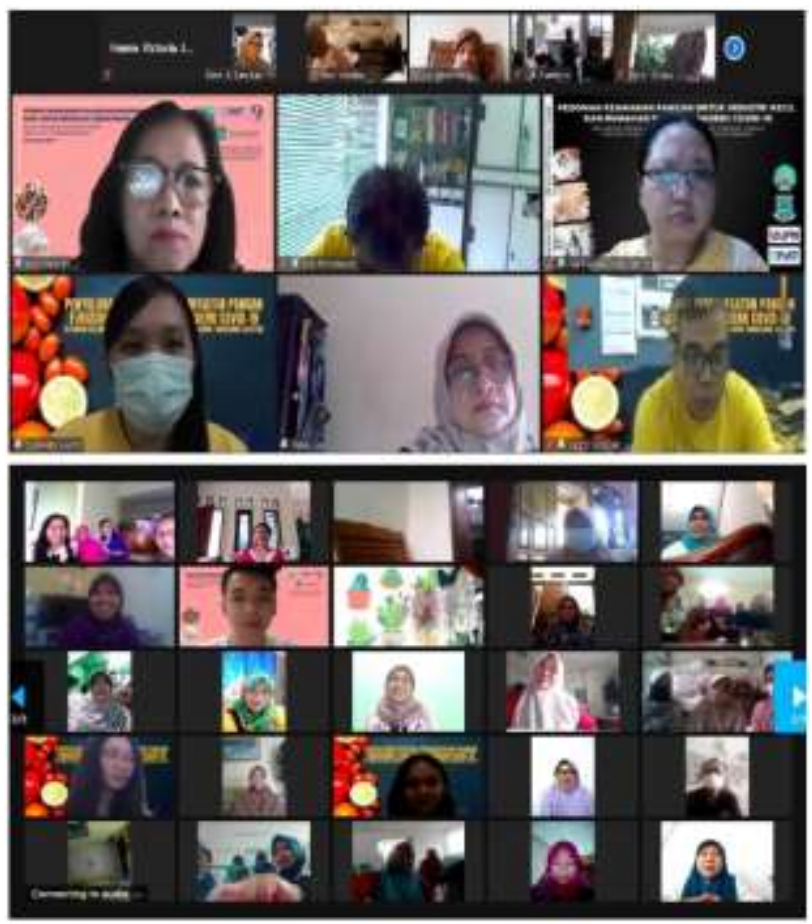

Gambar 5. Sesi diskusi yang berlangsung selama kegiatan penyuluhan antara peserta dengan Tim PkM Program Studi Teknologi Pangan UPH

\section{Dampak Kegiatan Penyuluhan bagi Forum KWT Sekar Arum}

Hasil evaluasi terhadap pelaksanaan kegiatan penyuluhan berdasarkan pengisian kuesioner menunjukkan bahwa peserta memberikan respon positif terhadap pelaksanaan penyuluhan di Forum KWT Sekar Arum Tangerang Selatan.

Sebanyak $98,85 \%$ peserta menyatakan bahwa kegiatan ini dapat diikuti dengan baik dan sangat bermanfaat, selain itu $89,66 \%$ peserta termotivasi untuk menerapkan pengetahuan yang diperoleh pada penyuluhan dalam aktivitas harian. Hal ini menunjukkan bahwa walaupun penyuluhan dilakukan secara webinar (zoom meeting) dan materi penyuluhan dalam bentuk slide presentasi (ms-powerpoint), peserta dapat menerima dan memahami materi penyuluhan dengan baik.
Hasil evaluasi berdasarkan kuesioner juga menunjukkan bahwa kegiatan PkM dalam bentuk penyuluhan ini dapat dilakukan lagi secara berkelanjutan, Para peserta juga menginginkan adanya kegiatan penyuluhan atau pelatihan yang dilaksanakan secara berkala dengan topik yang disesuaikan dengan kebutuhan dan potensi sumber daya yang ada

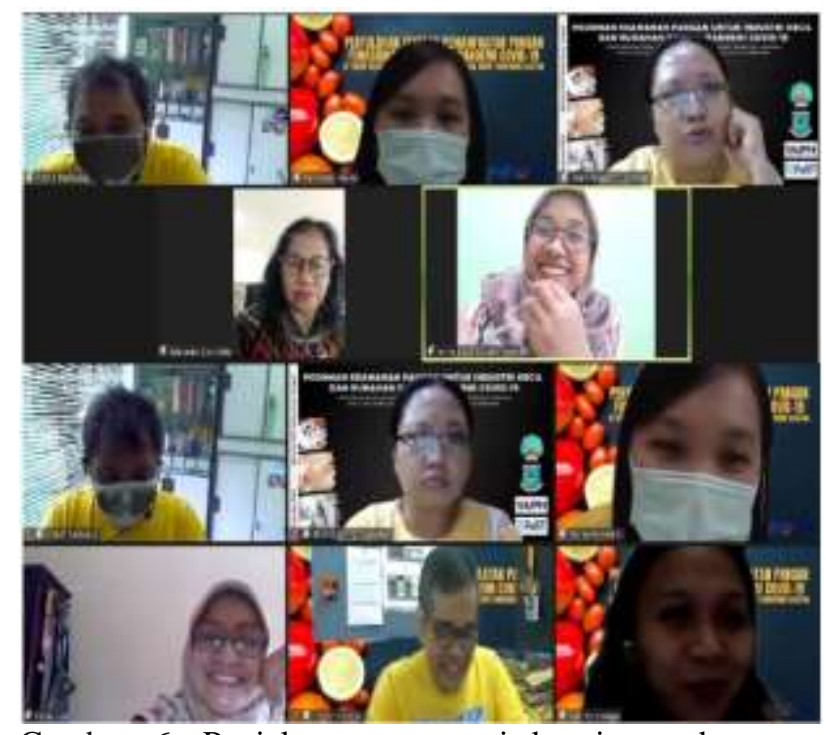

Gambar 6. Penjelasan mengenai kuesioner dan cara pengisiannya oleh Tim PkM-UPH

Setelah pelaksanaan kegiatan penyuluhan, pengurus Forum KWT Sekar Arum melaporkan tentang adanya kegiatan beberapa KWT yang melakukan pembuatan produk pangan fungsional seperti biskuit/cookies dengan penambahan sayuran dan minuman berbasis tanaman herbal yang dibudidayakan sebagai bentuk penerapan pengetahuan dan pengalaman yang diperoleh selama penyuluhan. Selain itu, juga dilaporkan bahwa sebagian besar anggota Forum KWT Sekar Arum semakin termotivasi untuk memanfaatkan tanaman pangan yang dibudidayakan seperti sayuran dan tanaman herbal untuk dikonsumsi sehari-hari dalam menjaga kesehatan tubuh di masa pandemi Covid-19. 


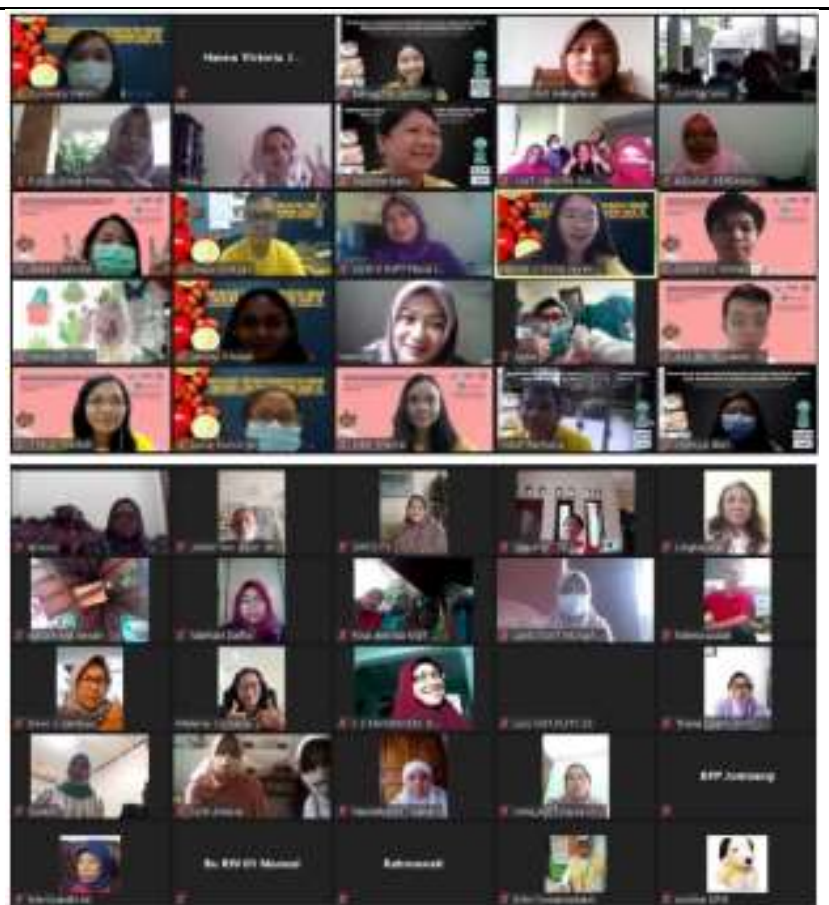

Gambar 7. Foto bersama seluruh peserta penyuluhan dengan Tim PkM Program Studi Teknologi Pangan UPH

Berdasarkan hasil evaluasi dan komunikasi yang dilakukan dengan Forum KWT Sekar Arum dan Dinas Ketahanan Pangan, Pertanian dan Perikanan Kota Tangerang Selatan, maka kegiatan PkM dalam bentuk penyuluhan ini diharapkan dapat dilakukan secara berkala dan berkelanjutan sesuai dengan potensi dan kondisi yang ada pada masyarakat Tangerang Selatan sehingga pada akhirnya dapat memberdayakan masyarakat dalam pemenuhan kebutuhan pangan dan peningkatan taraf kesehatan.

\section{KESIMPULAN}

Kegiatan PKM "Penyuluhan Pemanfaatan Pangan Fungsional Pada Masa Pandemi Covid-19 di Forum KWT Sekar Arum Tangerang Selatan" telah dilaksanakan dengan baik. Kegiatan ini dilakukan pada tanggal 5 November 2020 dan diikuti oleh 87 orang peserta dan 6 orang tim penyuluh, yang terdiri dari 4 orang dosen dan 2 orang mahasiswa Program Studi Teknologi Pangan. Bentuk kegiatan PkM ini berupa presentasi dan penjelasan materi pemanfaatan pangan fungsional pada masa pandemi Covid-19 serta diskusi terkait materi yang disampaikan kepada peserta.

Evaluasi terhadap pelaksanaan penyuluhan berdasarkan pengisian kuesioner menunjukkan $98,85 \%$ peserta menyatakan bahwa kegiatan penyuluhan dapat diikuti dengan baik dan sangat bermanfaat. Para peserta juga menginginkan adanya kegiatan penyuluhan atau pelatihan yang dilaksanakan secara berkala dengan topik yang disesuaikan dengan kebutuhan dan potensi sumber daya yang ada.

\section{UCAPAN TERIMAKASIH}

Penulis mengucapkan terima kasih kepada Lembaga Penelitian dan Pengabdian Masyarakat (LPPM) Universitas Pelita Harapan yang telah mendukung kegiatan Pengabdian kepada Masyarakat ini melalui skema PkM No. PM-003-K/FaST/X/2020.

Penulis juga mengucapkan terimakasih kepada Dinas Ketahanan Pangan, Pertanian dan Perikanan kota Tangerang Selatan yang turut mendukung pelaksanaan kegiatan penyuluhan ini.

\section{REFERENSI}

Aryanta I.W.R (2019). Manfaat Jahe Untuk Kesehatan. E-Jurnal Widya Kesehatan 1(2): 39-43

Astawan M. (2011). Pangan Fungsional untuk Kesehatan yang Optimal. Fakultas

Teknologi Pertanian IPB, Bogor.

Kusumayanti. H, Mahendrajaya R.T dan Hanindito S.B (2016). Pangan Fungsional Dari Tanaman Lokal Indonesia. METANA. 12(1):26-30

Soleh S.M. (2019). Karakteristik Morfologi Tanaman Kencur (Kaempferia Galanga L.) Dan Aktivitas Farmakologi. Farmaka, 17(2): 256-262

Siregar T.M, Soedirga L, Sinaga W dan Halim Y. (2020). Pelatihan Pembuatan Pasta Bumbu Dapur di Forum Kelompok Wanita Tani Sekar Arum Tangerang Selatan. Prosiding Konferensi Nasional PKM-CSR Vol. 3: 1199-1205 Subroto M.A. (2008). Real Food, True Health. Makanan Sehat Untuk Hidup Lebih Sehat. PT. Agro Media Pustaka, Jakarta 